\title{
Quality improvement programme for cardiovascular disease risk factor recording in primary care
}

\author{
Eeva Ketola, Raija Sipilä, Marjukka Mäkelä, Matti Klockars
}

\begin{abstract}
Objectives-Evaluation of the effect of a quality improvement programme on cardiovascular disease (CVD) risk factor recording and risk factor levels in a controlled study at two primary health care centres serving 26000 inhabitants in Northern Helsinki.

Methods-From a random sample of patient records from $1995(\mathrm{n}=1066), 1996$ $(n=1042)$, and $1997(n=1040)$ the frequency of CVD risk factor recording was measured and the changes in mean levels of total cholesterol, blood glucose, blood pressure, and body weight were monitored during the follow up period. The intervention programme (1995-1996) consisted of lectures and meetings of multiprofessional teams, development of local guidelines, and introduction of a structured risk factor recording sheet as part of the patient records.
\end{abstract}

Results-After the quality improvement period all risk factors were better recorded at the intervention station than at the control station $(p<0.001)$. More high risk CVD patients were detected from the general population at the intervention station. The mean values of most measured risk factors changed during the intervention. During the follow up period differences were observed between the two health stations in the time trends for body weight, body mass index (BMI), total cholesterol, and glucose levels. Risk factor levels of high risk patients receiving CVD treatment decreased during the intervention.

Conclusions-A simple quality improvement programme improved the practice of recording risk factors for CVD which resulted in earlier detection of patients with a high risk of developing the disease. (Quality in Health Care 2000;9:175-180)

Keywords: quality improvement; cardiovascular disease; risk factor recording; primary health care

The risk factors for cardiovascular disease (CVD) are well known and studies have shown the importance of both primary and secondary prevention. ${ }^{12}$ Prevention is effective when aimed at high risk groups ${ }^{3}$ but requires early identification of risk factors. However, in primary care the identification and recording of risk factors varies considerably. This is of particular concern in Finland as the population prevalence of CVD is high ${ }^{4}$ and the opportuni- ties for prevention are good as $85 \%$ of the population visit a physician yearly. ${ }^{5}$ When risk factors are not systematically documented, the benefits of early prevention are lost.

Besides poor documentation routines, the doctor's personal and long term knowledge of the patient may result in inadequate recording as GPs may choose to document only findings that are new or relevant to the presenting problem. The lack of sufficient time for consultations has also been an excuse. Grover et $a l^{6}$ suggested that, even though guidelines exist for targeting patients at high risk of CVD, accurate assessment of coronary risk remains difficult for many doctors. Although GPs do have the necessary knowledge, in practice there are difficulties in improving the work process. $\mathrm{Grol}^{7}$ discussed the importance of an iterative process in changing clinical practice. Educational interventions at the local level may improve motivation and commitment to the process of change.

In several studies the proportion of patients with current data on blood pressure in their patient record ranged from $22 \%$ to $98 \%,{ }^{8-13}$ data on weight from $20 \%$ to $87 \%,{ }^{810} 1213$ family history of CVD from $43 \%$ to $90 \%,{ }^{10} 1213$ smoking from $22 \%$ to $90 \%,{ }^{10}{ }^{12}{ }^{13}$ alcohol consumption from $0 \%$ to $58 \%,{ }^{14}$ and cholesterol measurements from $1 \%$ to $92 \% .^{1012} 1314$

High risk patients often experience their first cardiovascular event before any individual preventive actions have been taken. In Scandinavian primary health care it has been possible to integrate a large scale cardiovascular preventive programme into existing primary health care organisation..$^{15}$

Key messages

- Recognising high risk patients in primary care is essential in the prevention of unwanted outcomes of cardiovascular disease.

- The quality improvement programme was associated with a significant improvement in risk factor documentation.

- An improvement was seen in all observed risk factors immediately after the quality improvement training and continued over the next year.

- The quality improvement programme improved the preventive activity by primary care personnel.

- Small improvements were seen in risk factor levels of patients. 
- In patients with CVD interventions targeted to either single or multiple risk factors reduce CVD morbidity and mortality.

- Multifactorial interventions reduce levels of risk factors also in primary prevention, i.e. in patients without diagnosed CVD.

Box 1 Importance of risk factor reduction in cardiovascular disease (CVD). ${ }^{17}$

Although physicians do have knowledge about cardiac risk factors, it does not necessarily translate into preventive and interventive practice. In a WHO-WHL hypertension management audit project ${ }^{14}$ physicians expressed their concern about CVD risk factors and the importance of non-pharmacological treatment, but the results of a patient survey did not demonstrate any practical effects of such attitudes. Doctors also overestimate their own tendency to assess CVD risk factors. ${ }^{16}$ Reduction in risk factors for CVD has an effect on its outcome (box 1). In order to run CVD prevention and intervention programmes, sufficient data about early identification practice and risk factor documentation in primary care are needed.

In a UK randomised, controlled trial a screening and lifestyle intervention programme against coronary heart disease in primary care was implemented by research nurses making home visits. This Family Heart Study showed slight decreases in weight, blood pressure, and cholesterol values over 12 months. ${ }^{18}$ In the Oxcheck study health checks helped to manage hypertensive and hypercholesterolaemic patients but the overall effect was small, particularly in men. ${ }^{19} 20$

The present study was not a direct intervention for patients but a quality intervention for personnel, evaluating the effect of a quality improvement programme as a mechanism for improving risk factor levels. The effects of targeting interventions at primary care personnel, attempting to improve their knowledge of CVD risk factors and to increase their activity in the identification and treatment of high risk patients have not, to our knowledge, been studied previously.

The aims of our study were:

(1) to evaluate the quality of documentation of known CVD risk factors in patient records in Finnish primary care,

(2) to measure the effect of a quality improvement programme on the prevalence of the registration of measured risk factors in patient records, and

(3) to measure the effect of the programme on levels of CVD risk factors in the target population.

\section{Materials and methods}

Two suburban municipal health care centres with very similar populations $(11000$ and 15000 inhabitants) took part in the study in 1995-7. These populations were not overlapping and the proportion of subjects of working age was $65 \%$. Both are growing areas with an annual population turnover of 3-7\% (Helsinki Bureau of Statistics, personal communication).
In these areas $45 \%$ of the population use the primary care services annually. The rest of the population either does not need to consult or uses private services (mainly occupational health care) which are abundantly available in the capital region (box 2). The use of primary care services remained unchanged in the areas during the study.

A sample size of 500 patient records per health centre per year was estimated to detect a $10 \%$ difference in risk factor changes between the groups with $95 \%$ significance. A sample of the records of all patients of working age (18-65 years) was taken using two randomly chosen dates of birth per month. The study protocol was approved by the Helsinki City Health Centre ethical committee and permission to perform the study was granted by the City Health Officer as well as the chief physicians of the participating health centres. Permission to use the patient records for study was given by the Ministry of Social Affairs and Health.

The patient records in the participating health centres were traditional paper files. Two of the authors (EK and RS) collected the data from the records on study forms each year at the health centres. The latest recorded mean total cholesterol, blood pressure, weight, and blood glucose values were collected from each patient's records, together with data on age, sex, and CVD treatment (antihypertensive, lipid lowering, angina pectoris, decongestive, rhythm disturbance, or antiplatelet drugs).

QUALITY IMPROVEMENT PROGRAMME

A quality improvement programme was started after the first records audit at the intervention station, and the other health station with seven GPs remained as a control. In the quality improvement programme at the intervention station (1995-6) the personnel (five doctors, nurses, office assistants, and nurses' aids) were trained to detect high risk patients using a structured CVD risk factor form which was to be filled in for every patient over 18 years of age. The personnel attended four lectures (one on risk factors for CVD, one on the diagnosis and treatment of CVD, and two on diet

- Local authorities are responsible for providing both primary and secondary health care. Primary care is arranged through municipal health centres.

- Local authorities can provide services themselves, together with other authorities, or buy services from outside.

- Health centres offer both preventive and curative care. They have laboratory, radiography, and physiotherapy facilities and often also dieticians, psychologists, speech therapists, etc.

- Secondary health care is mainly provided regionally. Private services exist mainly in larger cities where they substitute for some primary care and offer a range of specialist services.

Box 2 Organisation of Finnish health care. 


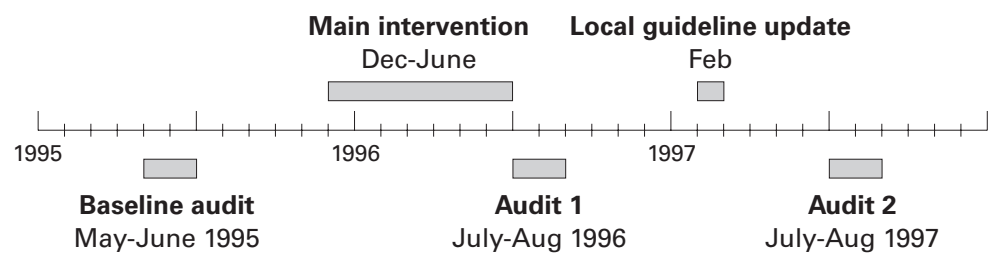

Figure 1 Flow diagram of the study.

counselling), participated in a quality circle, ${ }^{21}$ and constructed local guidelines for CVD patients. The audit results were fed back to the intervention station after every audit while the control station did not receive any information during the study.

The prevention targeted intervention programme was facilitated by one of the authors (EK) who also worked as one of the GPs at the intervention station. The programme was designed together with and run by a multiprofessional team which included a physician, nurse, physiotherapist, and dietician. Three experts from outside the health station (physiotherapist, preventive nurse, and dietician) participated as lecturers. Since 1996 the city of Helsinki has provided methodological training on quality circles for all health care personnel. Several members from each quality circle participated in this training (five days over six months) during the intervention period.

The local guidelines were constructed by the entire staff at the health centre. Their work in quality circles was based on identifying actual problems and familiarity with local circumstances. Local guidelines adopted the nationally recommended optimal levels and follow up schemes for blood pressure (BP) and cholesterol. $^{22-25}$ In addition, they included lifestyle recommendations for diet, physical exercise, alcohol consumption (including CAGE questions and minimal intervention instructions), and information on smoking cessation groups. A flow diagram of the study is shown in fig 1 .

RISK FACTOR MEASUREMENTS

All blood samples were taken at the laboratories of the participating health centres by trained personnel and analysed centrally at the Helsinki City Laboratory. Blood glucose and total cholesterol levels were measured by an enzymatic method using Beckmann's reagents and a Syncron analyser. Other measurements were performed by the doctors or nurses at their own offices in the health centres, similarly equipped with calibrated scales. Body weight was measured using SECA scales (kg), body mass index (BMI) was calculated as weight $(\mathrm{kg}) /\left(\right.$ height $\left.(\mathrm{m})^{2}\right)$, and BP was recorded using a calibrated mercury sphygmomanometer $(\mathrm{mm} \mathrm{Hg})$. Risk factor levels were the measurement results for each risk factor.

\section{STATISTICAL ANALYSES}

The SAS programme was used for statistical analyses. The data were analysed using the $t$ test for comparing mean risk factor measurements and the $\chi^{2}$ test or Fisher's exact test were used to compare levels of risk factor recording. General linear modelling for continuous variables and modelling categorical data were used to estimate time trends in the outcome measurements of the sample populations. Fluctuation in available patient records in the archives during the study period is likely due to people moving into or out of the area or because of deaths. This prompted us to analyse the results as a population based sample rather than as individual data.

\section{Results}

The annual samples varied slightly in size (table 1). The mean (SD) age of the patients varied from $38.6(12.0)$ to 41.5 (13.2) years and the proportion of women from $57.1 \%$ to $59.7 \%$. Samples from the control and intervention stations were similar in structure over the years of the study.

QUALITY OF DOCUMENTATION

Table 1 shows the frequency of risk factor recording at baseline in 1995, during 1996, and after the quality improvement programme in 1997. At baseline, smoking and alcohol use were better recorded at the control station but no other differences between the stations were observed.

EFFECT OF QUALITY IMPROVEMENT PROGRAMME ON DOCUMENTATION

After the quality improvement programme all risk factors were recorded better at the intervention station (table 1). The number of patient records showing high levels of risk

Table 1 Risk factor recording at intervention (IS) and control stations (CS) at baseline in year 1995 and at follow up in 1996 and 1997

\begin{tabular}{|c|c|c|c|c|c|c|c|c|c|}
\hline & \multicolumn{3}{|l|}{1995} & \multicolumn{3}{|l|}{1996} & \multicolumn{3}{|l|}{1997} \\
\hline & $\begin{array}{l}I S \\
n=514\end{array}$ & $\begin{array}{l}C S \\
n=552\end{array}$ & $p$ & $\begin{array}{l}I S \\
n=526\end{array}$ & $\begin{array}{l}C S \\
n=516\end{array}$ & $p$ & $\begin{array}{l}I S \\
n=515\end{array}$ & $\begin{array}{l}C S \\
n=525\end{array}$ & $p$ \\
\hline Weight & $11.0 \%$ & $11.0 \%$ & & $32.0 \%$ & $16.0 \%$ & $\star \star \star$ & $41.0 \%$ & $17.0 \%$ & $\star \star \star$ \\
\hline Height & $10.0 \%$ & $11.0 \%$ & & $31.0 \%$ & $15.0 \%$ & $\star \star \star \star$ & $40.0 \%$ & $16.0 \%$ & $\star \star \star$ \\
\hline BMI & $0.8 \%$ & $0.6 \%$ & & $9.0 \%$ & $2.0 \%$ & $\star \star \star$ & $20.0 \%$ & $3.0 \%$ & $\star \star \star$ \\
\hline $\mathrm{BP}$ & $43.0 \%$ & $41.0 \%$ & & $56.0 \%$ & $45.0 \%$ & $\star \star \star \star$ & $60.0 \%$ & $46.0 \%$ & 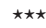 \\
\hline Blood glucose & $13.0 \%$ & $17.0 \%$ & & $24.7 \%$ & $18.4 \%$ & $\star$ & $30.7 \%$ & $18.9 \%$ & $\star \star \star$ \\
\hline Total cholesterol & $9.6 \%$ & $9.7 \%$ & & $19.2 \%$ & $12.2 \%$ & $\star \star$ & $23.5 \%$ & $12.4 \%$ & $\star \star \star \star$ \\
\hline Personal history of DM & $0.7 \%$ & $1.2 \%$ & & $45.0 \%$ & $30.0 \%$ & $\star \star \star \star$ & $50.0 \%$ & $32.0 \%$ & $\star \star \star \star$ \\
\hline Smoking habits & $6.0 \%$ & $12.0 \%$ & $\star \star \star \star$ & $31.0 \%$ & $21.0 \%$ & $\star \star \star$ & $39.0 \%$ & $23.0 \%$ & $\star \star \star$ \\
\hline Alcohol consumption habits & $1.0 \%$ & $5.0 \%$ & $\star \star$ & $21.0 \%$ & $10.0 \%$ & $\star \star \star \star$ & $20.0 \%$ & $6.0 \%$ & $\star \star \star \star$ \\
\hline Physical exercise habits & $0.3 \%$ & $0.1 \%$ & & $22.0 \%$ & $5.0 \%$ & $\star \star \star \star$ & $21.0 \%$ & $2.0 \%$ & $\star \star \star \star$ \\
\hline Family history of CVD & $5.0 \%$ & $6.1 \%$ & & $24.0 \%$ & $9.0 \%$ & $\star \star \star$ & $26.0 \%$ & $9.0 \%$ & $\star \star \star$ \\
\hline
\end{tabular}

${ }^{\star} \mathrm{p}<0.05,{ }^{\star \star} \mathrm{p}<0.01,{ }^{\star \star \star \star} \mathrm{p}<0.001$

$\mathrm{BMI}=$ body mass index; $\mathrm{BP}=$ blood pressure; $\mathrm{DM}=$ diabetes mellitus; $\mathrm{CVD}=$ cardiovascular disease. 
Table 2 Patient records showing high levels of risk factors at the intervention (IS) and control stations (CS) during years 1995-1997

\begin{tabular}{|c|c|c|c|c|c|c|c|c|c|c|c|c|}
\hline \multirow{3}{*}{$\begin{array}{l}\text { Increased } \\
C V D \text { risk by }\end{array}$} & \multicolumn{6}{|l|}{ IS } & \multicolumn{6}{|l|}{$C S$} \\
\hline & \multicolumn{2}{|c|}{1995} & \multicolumn{2}{|c|}{1996} & \multicolumn{2}{|c|}{1997} & \multicolumn{2}{|c|}{1995} & \multicolumn{2}{|c|}{1996} & \multicolumn{2}{|c|}{1997} \\
\hline & $n$ & $\%$ & $n$ & $\%$ & $n$ & $\%$ & $n$ & $\%$ & $n$ & $\%$ & $n$ & $\%$ \\
\hline 1 risk factor & 51 & 10 & 85 & 16 & 87 & 17 & 71 & 13 & 62 & 12 & 74 & 14 \\
\hline 2 risk factors & 21 & 4 & 44 & 8 & 38 & 7 & 25 & 5 & 41 & 8 & 40 & 8 \\
\hline $\begin{aligned} \geqslant & 3 \text { risk } \\
& \text { factors }\end{aligned}$ & 16 & 3 & 42 & 8 & 58 & 11 & 20 & 4 & 41 & 8 & 35 & 7 \\
\hline Total & 88 & 17 & 171 & 32 & 183 & 35 & 116 & 22 & 144 & 28 & 149 & 29 \\
\hline
\end{tabular}

factors also increased at the intervention station (table 2). At the end of the study (1997) this difference between the stations was clear $(p=0.024)$ but there was no significant difference in the time trends. A family history of CVD and diabetes, as well as alcohol consumption, smoking, and physical exercise were better accounted for at the intervention station after the programme.

The total number of registered hypertensive patients did not increase because there were more registrations of normal BP $(16.0 \%$ hypertensive at the intervention station in 1995 and $15.3 \%$ in 1997 compared with $15.2 \%$ and $12.4 \%$, respectively, at the control station). In 1995 8.2\% were registered hypercholesterolaemic at the intervention station and $18.6 \%$ in 1997 while at the control station the numbers were $7.4 \%$ and $10.9 \%$, respectively. Hypercholesterolaemic patients increased more at the intervention station but the difference in time trends did not reach significance $(p=0.55)$. The recorded prevalence of smokers increased from $3 \%$ in 1995 to $10 \%$ in 1997 at the intervention station and from $7 \%$ to $10 \%$ at the control station. There were more smokers among those taking CVD medications at the control station ( $9 \%$ versus $17 \%(p=0.031)$ ).

Among high risk patients the proportion prescribed CVD medication at the intervention and control stations were, respectively, $4 \%$ and $5 \%$ in $1995,6.5 \%$ and $7 \%$ in 1996 , and $8.5 \%$ and $7.2 \%$ in 1997 . Registration of risk factors in these groups varied from zero to $100 \%$, increasing annually over the study period.

\section{EFFECT ON RISK FACTOR LEVELS}

Table 3 shows the mean values of measured risk factors in the total sample. During the follow up period differences were observed between the two health centres in the time trends for body weight, BMI, total cholesterol, and glucose levels. The change in BP was minimal at both centres. Weight increased at both stations, but by less at the control station.
BMI showed a trend to increase at both stations, but significantly less so at the intervention station. Both total cholesterol and blood glucose levels decreased, significantly more at the intervention station. No differences were observed between men and women at either station.

Patients with prescribed CVD medication had higher systolic and diastolic BP values than the general population at both stations. Between 1995 and 1997 all mean risk factor levels of patients treated for CVD decreased at the intervention station (table 4): systolic blood pressure (SBP) by $9 \mathrm{~mm} \mathrm{Hg}$ and diastolic blood pressure (DBP) by $4 \mathrm{~mm} \mathrm{Hg}$, body weight by $1.9 \mathrm{~kg}, \mathrm{BMI}$ by $1.1 \mathrm{~kg} / \mathrm{m}^{2}$, total cholesterol by $0.5 \mathrm{mmol} / \mathrm{l}$, and blood glucose by $1.2 \mathrm{mmol} / 1$. At the control station the mean SBP and DBP did not change, body weight decreased by $1.0 \mathrm{~kg}$ and BMI by $0.9 \mathrm{~kg} / \mathrm{m}^{2}$, while the mean total cholesterol increased by $0.1 \mathrm{mmol} / 1$ and blood glucose by $0.4 \mathrm{mmol} / 1$. There were too few recorded data to estimate the statistical significance of these differences.

\section{Discussion}

In this study the quality of risk factor documentation was poor at the baseline. The quality improvement programme at the intervention station was associated with a significant improvement in risk factor recording. Improvements were also observed in two of the targeted risk factors-blood glucose and cholesterol levels; however, some of the change may have resulted simply from increased recording, probably providing more data from a relatively healthier section of the population.

QUALITY OF DOCUMENTATION

Before the intervention programme in 1995 CVD risk factors were documented suboptimally at both health centres. These results are in agreement with many other earlier studies. ${ }^{9-12}$ This suggests that the recognition of CVD risk factors was far from satisfactory. Even for patients who were prescribed CVD medication, the risk factor data in patient records were very incomplete, although more extensively recorded than in the whole sample. The usual explanations for inadequate risk factor recording-poor routines, lack of time, etc - are probably also relevant for the present study. The structured CVD risk factor form very probably helped the personnel at the intervention station to improve their recording practices.

Table 3 Mean (SD) values of measured risk factors in the general population sample

\begin{tabular}{|c|c|c|c|c|c|c|c|}
\hline & \multicolumn{3}{|c|}{ Intervention station } & \multicolumn{3}{|c|}{ Control station } & \multirow[b]{2}{*}{$p$ value } \\
\hline & 1995 & 1996 & 1997 & 1995 & 1996 & 1997 & \\
\hline $\mathrm{SBP}(\mathrm{mm} \mathrm{Hg})$ & $128(19.9)$ & $129(18.4)$ & $128(17.3)$ & $130(19.3)$ & $130(19.6)$ & $128(19.6)$ & 0.053 \\
\hline $\mathrm{DBP}(\mathrm{mm} \mathrm{Hg})$ & $80(11.7)$ & $81(11.3)$ & $81(10.7)$ & $82(12.6)$ & $82(11.6)$ & $81(11.3)$ & 0.052 \\
\hline Weight $(\mathrm{kg})$ & $70.5(14.2)$ & $72.4(15.0)$ & $73.0(15.6)$ & $68.9(14.7)$ & $75.0(18.2)$ & $71.0(16.8)$ & 0.0001 \\
\hline $\mathrm{BMI}\left(\mathrm{kg} / \mathrm{m}^{2}\right)$ & $23.6(9.0)$ & $26.8(4.0)$ & $27.0(5.0)$ & $27.6(7.0)$ & $28.2(3.9)$ & $28.0(4.2)$ & 0.0001 \\
\hline Total cholesterol $(\mathrm{mmol} / \mathrm{l})$ & $6.2(1.4)$ & $5.9(1.1)$ & $5.8(1.0)$ & $6.0(1.0)$ & $6.0(1.0)$ & $6.1(1.0)$ & 0.0012 \\
\hline Blood glucose $(\mathrm{mmol} / \mathrm{l})$ & $5.4(1.6)$ & $5.3(1.5)$ & $5.1(1.1)$ & $5.5(1.2)$ & $5.4(1.3)$ & $5.3(1.3)$ & 0.0004 \\
\hline
\end{tabular}

SBP = systolic blood pressure DBP = diastolic blood pressure.

${ }^{\star}$ Difference in time trends between intervention (IS) and control stations (CS) 
Table 4 Mean values of measured risk factors in persons taking cardiovascular disease medication

\begin{tabular}{|c|c|c|c|c|c|c|c|}
\hline & \multicolumn{3}{|l|}{ IS } & \multicolumn{3}{|l|}{$C S$} & \multirow{2}{*}{$\begin{array}{l}\text { No of } \\
\text { observations }\end{array}$} \\
\hline & 1995 & 1996 & 1997 & 1995 & 1996 & 1997 & \\
\hline Yearly no of patients & 21 & 34 & 44 & 28 & 36 & 38 & \\
\hline $\mathrm{SBP}(\mathrm{mm} \mathrm{Hg})$ & 147 & 144 & 138 & 145 & 145 & 145 & $17-44$ \\
\hline $\mathrm{DBP}(\mathrm{mm} \mathrm{Hg})$ & 90 & 89 & 86 & 90 & 90 & 90 & $17-44$ \\
\hline Weight (kg) & 80.7 & 80.7 & 78.8 & 85.6 & 85.6 & 84.6 & $17-36$ \\
\hline $\operatorname{BMI}\left(\mathrm{kg} / \mathrm{m}^{2}\right)$ & $\star \star$ & 29.3 & 28.2 & 29.0 & 29.0 & 28.1 & $0-24$ \\
\hline Total cholesterol $(\mathrm{mmol} / \mathrm{l})$ & 6.3 & 6.1 & 5.8 & 6.3 & 6.3 & 6.4 & $8-36$ \\
\hline Blood glucose $(\mathrm{mmol} / \mathrm{l})$ & 6.5 & 5.7 & 5.3 & 5.4 & 5.6 & 5.8 & $9-36$ \\
\hline
\end{tabular}

$\mathrm{SBP}=$ systolic blood pressure, $\mathrm{DBP}=$ diastolic blood pressure, $\mathrm{BMI}=$ body mass index.

${ }^{\star}$ Patients with risk factor registered (variation over three years)

${ }^{\star \star}$ No BMI measurements in this group at baseline 1995 .

\section{THE QUALITY IMPROVEMENT PROGRAMME AND \\ ITS EFFECTS}

In our study the difficulty in conducting a quality improvement programme was overcome by using a multiprofessional team from the planning and start of the programme. When the professionals teamed up to solve the practical problems experienced in their own working environment, they enjoyed the process and completed it well. A general quality improvement movement in the Helsinki City Health Services also supported our intervention both mentally and in practice.

Improvement in audit results motivated the doctors at the intervention station. We tried to avoid a possible contamination effect between the two stations by not reporting the audit results at the control station and asking the personnel at the intervention station not to discuss the quality improvement programme and audit results with the control station personnel. The stations did not have any occasions where the quality improvement project could be discussed, though the doctor in charge of the control station did know of the study.

After the end of the study the control station started an audit of CVD risk factor recording using the data collected for the study. They were also the first to adopt the guideline and other materials directly from the intervention station. At present, parts of the guideline and linked materials are used by most of the 32 health centres in the Helsinki City Health Centre where they are available to primary care professionals through the joint intranet service. In this study quality improvement activities were a useful approach in primary care, and we expect they would be useful in other Finnish health centres. However, the transferability of our approach to units outside Finland is difficult to estimate.

The recording of all CVD risk factors increased significantly at the intervention station during the quality improvement programme, but a regression towards the mean must be accounted for. Our results resemble those of Fullard et $a l^{26}$ who used a facilitator to help to set up and supervise the screening and audit of patient records. Pringle ${ }^{12}$ also reported a quality improvement programme which increased the practice of risk factor recording. In our study the recorded proportion of high risk patients increased more at the intervention station than at the control station. This indicates a true effect of the quality programme and has not been reported before for populations at risk for CVD.

EFFECT ON RISK FACTOR LEVELS

In our study the risk factor levels in the population both improved and deteriorated: blood pressure remained similar, weight and BMI deteriorated, while cholesterol and glucose levels improved at the intervention station compared with the control station. This variation may be explained by several factors. Our follow up time may have been too short for systematic improvements in risk factor levels to occur. The decrease in total cholesterol and blood glucose levels may partly result from regression towards the mean. In recent years it has become popular to test cholesterol levels, supported by health discussions in the press. The most likely explanation, however, is the fact that previously these values had been checked in only a very few individuals who consulted primary care, and then possibly predominantly in those seen to be at high risk for CVD. The increase in testing initiated by the personnel would then include a relatively larger proportion of low risk persons and this would decrease the mean values.

Blood pressures were higher in the subgroup receiving treatment for CVD than in the total sample. In subgroup analysis both SBP and DBP decreased among CVD treated patients at the intervention station but not at the control station, but the difference did not reach statistical significance. As some of the patients were similar each year, the statistical method used may underestimate the levels of significance. The result may reflect a true effect of the quality programme on high risk patients which should be confirmed in a larger study.

\section{Conclusions}

A quality improvement programme using structured follow up sheets in the patient records was associated with an improvement in recording of risk factors for CVD and high risk patients were better identified in primary care. We recommend systematic screening for risk factors in primary care. Improved recording of risk factors will benefit not only patients with CVD, but also other patient groups such as those with musculoskeletal diseases and pulmonary disease. Earlier detection of high risk patients facilitates more effective prevention.

1 Scandinavian Simvastatin Survival Study Group. Randomised trial of cholesterol lowering in 4444 patients with coronary heart disease: The Scandinavian Simvastatin Surcoronary heart disease: The Scandinavian
vival Study. Lancet 1994;344:1383-9.

2 Sheperd J, Cobbe SM, Ford I, et al. Prevention of coronary heart disease with pravastatin in men with hypercholesterolemia. N Engl f Med 1995;333:1301-7.

3 Garber AM, Browner WS, Hulley SB. Cholesterol screening in asymptomatic adults, revisited. Ann Intern Med 1996; 124:518-31.

4 Salomaa V, Vartiainen E, Korhonen HJ, et al. Cardiovascular risk factors in hypertensive patients and in population in 1982-1992 (in Finnish). Suomen Lääkärilehti 1994;49: 1926-32.

5 Aro S. Demonstration of population responsibility in primary care (in Finnish). Sosiaali- ja terveyshallituksen raportteja 1991;24:42-3.

6 Grover SE, Lowensteyn I, Esrey KL, et al. Do doctors accurately assess coronary risk in their patients? Preliminary rately assess coronary risk in their patients? Preliminary
results of the coronary health assessment. BMF 1995;310: results

7 Grol R. Beliefs and evidence in changing clinical practice. BMf 1997;315:418-21. 
8 Maitland JM, Reid J, Taylor RJ. Two stage audit of cerebrovascular and coronary heart disease risk factor recording: the effect of case finding and screening programmes. Br 7 Gen Pract 1991;41:144-6.

Skinner JS, Farrer M, Albers CJ, et al. Risk factor control five years after coronary bypass grafting. $\mathcal{F} R$ Coll Physicians London 1996;30:136-41.

10 Meagher PFK, Deery C, Linton AF, et al. An audit of hypertensive care in general practice. Irish Med f 1993;86: $20-2$.

11 Kurji KM, Haines AP. Detection and management of hypertension in general practices in north west London. BMF 1984;288:903-6.

12 Pringle $M$. Preventing ischemic heart disease in one general practice: from one patient, through clinical audit, needs assessment, and commissioning into quality improvement. BMF 1998;317:1120-3.

13 Eaton CB, McQuade W, Glupczynski D. A comparison of primary versus secondary cardiovascular disease prevention in academic family practice. Family Med 1994;26:587tion in
92.

14 Wilhelmsen L, Strasser T, on behalf of the Study Collaborators. WHO-WHL Hypertension Management Audit Project: summary publication. If Human Hypertension 1993;7:257-63.

15 Hellénius M-L, de Faire U, Krakau I, et al. Prevention of cardiovascular disease within the primary health care system. Feasibility of a prevention programme within the Sollentuna primary health care catchment area. Scand $f$ Primary Health Care 1993;11:68-73.

16 Leaf DA, Neighbor WE, Schaad D, et al. A comparison of self-report and chart audit in studying resident physician assessment of cardiac risk factors. $\mathcal{f}$ Gen Intern Med 1995 10:194-8.

17 Ketola E, Sipilä R, Mäkelä $M$. Effectiveness of individual lifestyle interventions in reducing cardiovascular disease and risk factors. Ann Med 2000;32:239-51.
18 Family Heart Study Group. Randomised controlled trial evaluating cardiovascular screening and intervention in general practice: principal results of British family heart study. BMF 1994;308:313-20.

19 Imperial Cancer Research Fund Oxcheck Study Group. Prevalence of risk factors for heart disease in OXCHECK trial: implications for screening in primary care. BMf 1991;302:1057-60.

20 Imperial Cancer Research Fund Oxcheck Study Group. Effectiveness of health checks conducted by nurses in primary care: results of the OXCHECK study after one year. BMF 1994;308:308-12.

21 Vaaranen V, Outinen M. TOKYO-step: quality improvement workbook (in Finnish). Helsinki: Työterveyslaitos, 1994.

22 Suomen Sydäntautiliiton verenpainetyöryhmän suositus. National guideline for diagnosis and treatment of hypertension (in Finnish). Suomen Lääkärilehti 1994;49:183140

23 Suomen Sydäntautiliiton työryhmän kannanotto. Prevention of hypertension (in Finnish). Suomen Lääkärilehti 1994;49:1821-28.

24 Suomen Sisätautilääkärien yhdistyksen, Suomen Kardiologisen Seuran, Suomen Sydäntautiliiton, Kunnallislääkäreiden ja Suomen teollisuuslääketieteen Yhdistyksen työryhmän suositus. Diagnosis and treatment of hypercholesterolemia and other hyperlipidemias in adult patients (in Finnish). Duodecim 1993;109:481-501.

25 Syvänne M, Frick HM, Taskinen M-R. Secondary prevention in coronary heart disesase: treatment of dyslipidemias is clarifying (in Finnish). Suomen Lä̈̈kärilehti 1993;48: 2417-24.

26 Fullard E, Fowler G, Gray M. Promoting prevention in primary care: controlled trial of low technology, low cost approach. BMf 1987;294:1080-2. 